\title{
AVES E VEGETAÇÃO EM UM BAIRRO RESIDENCIAL DA CIDADE DE SÃO PAULO (SÃO PAULO, BRASIL)
}

\author{
Maria Martha Argel-de-Oliveira ${ }^{1}$
}

\begin{abstract}
BirdS AND VEgETATION IN A RESIDENTIAL QUARTER IN SÃo PAulo ctTy (SÃo Paulo, BraZil.). From 1978 to 1991, 48 bird species have exploited some kind of resource in a residential quarter reasonably well provided of vegetation. There was a predominance of species with generalist feeding habits (omnivores and non-specialized insectivores), forest edge or secondary growth dwellers, and species that feed and nest in arboreal and shrub layers. Only 23 species are certain or probable residents; the presence of others is due to migration or to displacement of populational excedents coming perhaps from nearby urban parks. Although the vegetation is not exactly profuse, it is enough to be exploited by many forest species. As the city of São Paulo confines with the Atlantic Forest, this kind of urban vegetation may be important to the maintenance not only of resident populations but also of vagrant birds from the surroundings, including some rare or little known species.
\end{abstract}

KEY WORDS. Urban avifauna, São Paulo, Brazil

Já há algumas décadas existe interesse pelo estudo das aves nas cidades brasileiras. Tal interesse tem originado um certo número de publicações, em sua maioria listas de espécies de parques, campi universitários, remanescentes de vegetações nativas e outras áreas verdes. Escassos trabalhos tratam de áreas realmente urbanizadas e menos ainda analisam a relação da avifauna com o ambiente. Existem poucos elementos, portanto, para se determinar de que forma o processo de urbanização afeta uma avifauna regional, e correspondentemente, de que forma ocorre a utilização desse novo ambiente pelas aves.

A situação não é diferente para a cidade de São Paulo, embora as primeiras informações sobre suas aves datem já de princípios do século passado. J. Natterer e P.W. Lund coletaram alguns exemplares ao passarem por essa localidade (PELZELN 1871; PINTO 1950). IhERING (1898) e PINTO (1937, 1944) mencionaram também espécimes coletados na área. Nenhum deles tinha, porém, intenção de estudar especificamente a avifauna paulistana. É MrTCHELL (1957) que, pela primeira vez, apresenta não só as espécies vistas em São Paulo, mas também descreve e faz comentários sobre o ambiente dos locais onde as registrou, inclusive mencionando formas de exploração de recursos como alimentos, locais de forrageamento e de nidificação.

É recente a preocupação em conhecer a composição da avifauna paulistana e saber como as espécies estão distribuídas na cidade (ARGEL-DE-OLIVEIRA 1987).

1) Departamento de Zoologia, Instituto de Biologia, Universidade Estadual de Campinas, Caixa Postal 6109. 13083-970 Campinas, São Paulo, Brasil.

Correspondências: Av. Irerê, 198, 04064000 São Paulo, São Paulo, Brasil. 
Até o momento, porém, conhece-se com maior detalhe somente a fauna de aves de uma área verde, a Cidade Universitária Armando de Salles Oliveira (MATARAZZO-Neuberger 1990b; HöFling \& CAMARGo 1993).

Uma vez que é quase completo o desconhecimento da avifauna que explora o ambiente efetivamente urbano na cidade de São Paulo, este trabalho procura caracterizar ecologicamente as espécies que ocorrem em um bairro residencial e determinar qual o uso que fazem da área. Também é tecida uma discussão acerca da importância, para a avifauna, da vegetação existente na cidade, mas fora das áreas verdes.

\section{ÁrEA de ESTUdo}

O bairro do Planalto Paulista é, segundo SÃo PAULO (1988), predominantemente residencial, de padrão alto-médio, com pequena ocorrência de edifícios de apartamentos; as ruas, asfaltadas, são arborizadas em alinhamentos descontínuos, onde predomina Caesalpina peltophoroides Benth. (sibipiruna, Leguminosae nativa), com a ocorrência de outras espécies floríferas. O bairro é considerado um bairro arborizado, em que a vegetação predominante é a da arborização de rua, diferentemente dos bairros-jardins, onde boa parte dos grandes lotes é ocupada por jardins e quintais, cuja vegetação funde-se à farta arborização viária. A maioria da vegetação arbórea viária foi plantada em meados da década de setenta. Segundo a publicação acima, em 1988 essa vegetação ainda não havia atingido o porte adulto e poucas ruas tinham seu leito sombreado pelas copas cruzadas sobre a via.

O bairro situa-se em plena mancha urbana da região metropolitana de São Paulo, entre duas grandes áreas verdes, distando cerca de $2.200 \mathrm{~m}$ do Parque do Ibirapuera $\left(1.584 .000 \mathrm{~m}^{2}\right.$ de área) e aproximadamente $3.800 \mathrm{~m}$ do Parque Estadual das Fontes do Ipiranga (PEFI, $5.428 .156 \mathrm{~m}^{2}$ de área).

Nos jardins residenciais e na arborização de rua da área de estudo estão presentes, entre outras, as seguintes espécies vegetais que, segundo a bibliografia, representam fontes de alimento para as aves: Archontophoenix cunninghamiana Wendl. \& Drude (seafórtia, Palmae exótica), Eucalyptus sp. (eucalipto, Myrtaceae exótica), Ficus carica L. (figueira, Moraceae exótica), Hibiscus rosasinensis L. (hibisco, Malvaceae exótica), Hovenia dulcis Thunb. (uva-japonesa, Rhamnaceae exótica), Mangifera indica L. (mangueira, Anacardiaceae exótica), Morus nigra L. (amoreira, Moraceae exótica), Persea americana Mill. (abacateiro, Lauraceae exótica), Plumeria sp. (jasmim-manga, Apocynaceae nativa), Psidium guajava L. (goiabeira, Myrtaceae nativa), Pyracantha sp. (piracanta, Rosaceae exótica), Spathodea campanulata Beauv. (tulipa-africana, Bignoniaceae exótica), Syagrus romanzoffiana (Cham) Glassm (jerivá, Palmae nativa) e Tabebuia sp. (ipêamarelo, Bignoniaceae nativa)

\section{MATERIAL E MÉTODOS}

Durante um ano (agosto de 1990 a julho de 1991), foram realizadas, por mês, dez sessões diárias de observações, com a duração de 30 minutos, em horário padronizado (tão logo houvesse luminosidade suficiente para distinguir cores com clareza) sempre a partir de um mesmo ponto, totalizando assim 60 horas de 
observação. Foi usado um binóculo Zeiss-Jena $8 \times 32$. As dimensões da área de observação eram de aproximadamente $200 \times 300$, mas a distância máxima de detecção variava entre as espécies, dependendo de seus hábitos (por exemplo, altura de vôo, intensidade de vocalização).

Eram registradas todas as espécies de aves vistas ou ouvidas, incluindo aquelas que apenas sobrevoavam a área e espécies obviamente escapadas de cativeiro. O uso dessa metodologia padronizada permitiu comparação quanto à freqüência de ocorrência das diferentes espécies e quanto à sazonalidade da presença de várias delas.

Ao longo desse ano fez-se também o registro de aves detectadas fora dos intervalos de observação. São apresentados na tabela II ainda os resultados de observações realizadas ad libitum nos anos de 1978, 1982-89 e janeiro-julho de 1990. Tais dados não são adequados para tratamentos numéricos, pois em geral referem-se apenas a aves de avistamento menos freqüente. Aumentam, porém, o conhecimento da sazonalidade dessas aves, revelando, ainda, espécies muito pouco freqüentes que não foram detectadas durante as observações padronizadas.

\section{RESULTADOS E DISCUSSÃO}

No decorrer das observações padronizadas foram detectadas 49 espécies de aves, que correspondem a $94 \%$ das espécies registradas no período de agosto de 1990 a julho de 1991 (52 espécies) e a $73 \%$ de todas as espécies de aves observadas desde 1978 na área (67 espécies) (Tabs I, II). O estudo padronizado resultou no registro de 13 espécies não observadas anteriormente (19\% do número total de espécies).

Essas espécies foram reunidas em seis categorias, conforme a freqüência de detecção e $o$ uso que fizeram do ambiente.

Residentes: quinze das dezesseis espécies com freqüência igual ou superior a 0,60 são comuns na área durante $o$ ano todo e se utilizam da vegetação e/ou das edificações para sua alimentação, pernoite e, na maioria dos casos, para atividades relacionadas à reprodução: Columba livia Gmelin, 1789, Columbina talpacoti (Temminck, 1811), Brotogeris tirica (Gmelin, 1788), Eupetomena macroura (Gmelin, 1788), Amazilia lactea (Lesson, 1832), Pitangus sulphuratus (Linnaeus, 1766), Todirostrum cinereum (Linnaeus, 1766), Notiochelidon cyanoleuca (Vieillot, 1817), Troglodytes aedon Vieillot, 1807, Turdus rufiventris Vieillot, 1818, Molothrus bonariensis (Gmelin, 1789), Coereba flaveola (Linnaeus, 1758), Thraupis sayaca (Linnaeus, 1766), Zonotrichia capensis (Müller, 1776) e Passer domesticus Linnaeus, 1758. Essas espécies são comuns também em outros bairros residenciais da cidade, salvo, talvez, $T$. cinereum (obs. pess.).

Prováveis residentes: várias espécies, registradas com freqüência menor, parecem ser também residentes na área. Cinco espécies tiveram entre 0,17 e 0,42 de freqüência: Buteo magnirostris (Gmelin, 1789), Serpophaga subcristata (Vieillot, 1817) e Thraupis palmarum (Wied, 1821) foram registrados em praticamente todos os meses, enquanto os registros de Elaenia flavogaster (Thunberg, 1822) e de Estrilda astrild (Linnaeus, 1758) estiveram hem distribuídos 
Tabela I. Aves observadas no bairro do Planalto Paulista (São Paulo) de agosto de 1990 a julho de 1991. com o número de intervalos padronizados em que cada espécie foi observada por mês (ver metodologia no texto). Entre parênteses, número de dias em que houve registro fora dos intervalos padronizados.

\begin{tabular}{|c|c|c|c|c|c|c|c|c|c|c|c|c|c|}
\hline Espécies & Ago & Set & Out & Nov & Dez & Jan & $\mathrm{Fev}$ & Mar & Abr & Mai & Jun & Jul & $\mathrm{Fr} \cdots$ \\
\hline Phalacrocorax olivaceus & $5(3)$ & $7(1)$ & 8 & 3 & 2 & $5(1)$ & 5 & $5(1)$ & 5 & $8(1)$ & 9 & 10 & 0,60 \\
\hline Casmerodius albus & 1 & 1 & 3 & 1 & - & 1 & $1(1)$ & - & - & 3 & 2 & 3 & 0,13 \\
\hline Nycticorax nycticorax " & & & - & . & 2 & - & . & - & - & - & - & - & 0,02 \\
\hline Dendrocygna viduata & (3) & - & - & (1) & - & - & - & $\cdot$ & (1) & 3 & (2) & - & 0,03 \\
\hline Coragyps atratus & $\cdot$ & - & - & - & - & - & $\cdot$ & $\cdot$ & - & $\cdot$ & 1 & (1) & 0.01 \\
\hline Buteo magnirostris & $3(2)$ & & 2 & $2(1)$ & $3(1)$ & 3 & 7 & $2(2)$ & $1(1)$ & 2 & 3 & 1 & 0,24 \\
\hline Vanellus chilensis & (3) & 1 & $1(1)$ & (2) & (2) & - & - & - & (2) & $5(1)$ & $1(2)$ & 1 & 0,07 \\
\hline Columba livia & $9(3)$ & 10 & 10 & 10 & 10 & 10 & 10 & $10(1)$ & 10 & 10 & 10 & 10 & 0,99 \\
\hline Columbina talpacoti & $9(4)$ & 10 & 10 & 10 & 10 & 10 & 10 & $10(1)$ & 10 & 10 & 10 & 10 & 0,99 \\
\hline Brotogeris tirica & $10(4)$ & 8 & 10 & 10 & 10 & 10 & 9 & $10(1)$ & 10 & 10 & 10 & 10 & 0,97 \\
\hline Brotogeris versicolurus * & 1 & - & - & - & - & - & - & - & - & - & - & - & 0,01 \\
\hline Amazona aestiva & - & - & - & 1 & - & - & - & - & . & - & - & - & 0,01 \\
\hline Coccyzus euteri - & - & - & - & - & 1 & - & - & - & - & $\cdot$ & - & - & 0,01 \\
\hline Piaya cayana & - & - & - & - & - & - & - & (1) & - & - & - & - & - \\
\hline Streptoprocne zonaris & . & - & - & . & - & - & - & - & . & - & - & (1) & - \\
\hline Chaetura andrei & 1 & 7 & 8 & 9 & 8 & $6(1)$ & 4 & 9 & 1 & - & - & - & 0,44 \\
\hline Eupetomena macroura & $6(4)$ & 4 & 8 & 9 & 9 & 10 & 6 & $8(2)$ & 10 & 10 & 8 & 6 & 0,78 \\
\hline Amazilia lactea & $8(3)$ & 5 & 8 & 10 & $9(1)$ & 10 & 10 & $10(1)$ & 9 & 9 & 10 & 10 & 0,90 \\
\hline Furnarius rufus & - & 2 & - & & - & - & - & & & - & - & - & 0,02 \\
\hline Synallaxis spixi & - & - & - & - & - & 1 & - & - & . & - & - & - & 0.01 \\
\hline Machetornis rixosa & - & - & 1 & - & (1) & - & - & $\cdot$ & 1 & $\cdot$ & $\cdot$ & $\cdot$ & 0,02 \\
\hline Tyrannus melancholicus & . & 1 & $3(1)$ & $6(1)$ & 7 & 8 & $6(2)$ & $3(2)$ & 2 & . & - & $\cdot$ & 0,30 \\
\hline Myiodynastes maculatus . & - & - & 1 & . & - & - & - & - & . & - & - & - & 0,01 \\
\hline Myiozetetes similis & . & - & - & - & (1) & - & - & - & . & - & (2) & - & - \\
\hline Pitangus sulphuratus & $10(4)$ & 10 & 10 & 10 & 10 & 10 & 10 & $10(1)$ & 10 & 10 & 10 & 10 & 1,00 \\
\hline Todirostrum cinereum & $4(2)$ & 6 & 9 & 4 & 1 & 9 & $8(1)$ & $8(1)$ & $6(1)$ & $5(1)$ & 7 & $6(1)$ & 0,61 \\
\hline Serpophaga subcristata & $1(1)$ & 1 & (1) & - & $1(1)$ & 1 & - & 6 & $1(1)$ & (2) & $2(1)$ & 9 & 0,18 \\
\hline Elaenia flavogaster ${ }^{*}$ & $4(2)$ & $2(1)$ & - & $2(1)$ & $6(1)$ & - & - & 3 & 3 & - & 1 & - & 0,17 \\
\hline Elaenia sp. & - & - & - & 1 & - & 1 & - & - & . & - & - & - & 0,02 \\
\hline Camptostoma obsoletum & - & - & 2 & (1) & . & - & $4(1)$ & 2 & - & (1) & $\cdot$ & - & 0,07 \\
\hline Progne chalybea & - & - & . & - & - & - & - & - & . & - & - & 1 & 0,01 \\
\hline Notiochelidon cyanoleuca & $8(3)$ & 7 & 9 & 10 & 10 & 10 & 10 & $7(1)$ & 4 & $1(1)$ & 3 & 4 & 0,69 \\
\hline Troglodytes aedon & $10(4)$ & 10 & 10 & 10 & 10 & 10 & 10 & $10(1)$ & 10 & 10 & 10 & 10 & 1,00 \\
\hline Platycichla flavipes * & - & - & - & - & - & - & - & . & - & - & - & 1 & 0,01 \\
\hline Turdus rufiventris & $10(4)$ & 10 & 10 & 10 & 10 & 8 & 10 & $10(1)$ & 10 & 10 & 9 & 10 & 0,97 \\
\hline Turdus amaurochalinus & 1 & - & - & & - & - & - & - & & - & - & - & 0,01 \\
\hline Turdus albicollis & $1(1)$ & - & - & . & - & - & - & & & - & & - & 0,01 \\
\hline Cyclarhis gujanensis & - & - & - & 2 & - & - & - & - & . & - & - & - & 0,02 \\
\hline Molothrus bonariensis & $10(2)$ & 10 & 10 & 10 & 8 & 10 & 9 & $10(1)$ & 7 & 10 & 10 & 10 & 0,95 \\
\hline Leistes superciliaris * & - & - & 1 & - & - & - & - & . & . & - & - & - & 0,01 \\
\hline Parula pitiayumi & - & - & . & - & - & - & - & - & - & 4 & 5 & - & 0,07 \\
\hline Coereba flaveola & $10(4)$ & 10 & 10 & 10 & 10 & 10 & 10 & $10(1)$ & 10 & 10 & 10 & 10 & 1,00 \\
\hline Tangara peruviana ${ }^{*}$ & 2 & . & . & . & . & . & - & - & - & - & - & - & 0,02 \\
\hline Tangara cayana * & $4(2)$ & 1 & - & . & . & - & 1 & 2 & 3 & 3 & 1 & - & 0,13 \\
\hline Thraupis sayaca & $10(4)$ & $8(1)$ & 10 & 10 & 10 & 10 & 10 & $10(1)$ & 10 & 10 & 10 & 9 & 0,97 \\
\hline Thraupis palmarum & $7(1)$ & 2 & 2 & & 1 & 2 & 6 & 5 & 5 & 6 & 9 & 6 & 0,43 \\
\hline Piranga flava & $\cdot$ & - & - & . & - & - & - & - & 1 & - & - & - & 0.01 \\
\hline Tachyphonus coronatus " & $9(2)$ & 2 & 1 & . & . & - & - & - & - & - & - & - & 0,10 \\
\hline Thiypopsis sordida & 4 & 2 & 1 & - & . & - & 2 & 4 & 3 & 2 & - & 1 & 0,16 \\
\hline Zonotrichia capensis & $10(3)$ & 10 & 10 & 10 & 10 & 9 & $4(1)$ & $8(1)$ & 10 & 9 & 9 & 9 & 0,91 \\
\hline Passer domesticus & $9(3)$ & 10 & 10 & 10 & 10 & 10 & 10 & $10(1)$ & 10 & 10 & 10 & 10 & 0,99 \\
\hline Estrilda astrild & - & - & 1 & 1 & $2(1)$ & 3 & 5 & 6 & $6(1)$ & 3 & - & 3 & 0,25 \\
\hline
\end{tabular}

*. Número de registros da espécie/n $\mathrm{n}^{\mathrm{o}}$ total de períodos de observação $(\mathrm{N}=120)$

**. Espécies não registradas anteriormente. 
ao longo do ano. À exceção de E. flavogaster, essas espécies também tiveram registros numerosos em anos anteriores (Tab. II). A freqüência de detecção relativamente baixa pode ser devida a uma densidade populacional baixa e/ou a áreas de vida que extrapolavam a área de detecção. Talvez seja o caso, ainda, de três espécies com índice de freqüência variando entre 0,07 e 0,16 e registros bem distribuídos ao longo do ano: Camptostoma obsoletum (Temminck, 1824), que foi detectado com alguma freqüência também de abril a junho de 1984 (Tab. II); Thlypopsis sordida (Lafresnaye \& d'Orbigny, 1837), com vários registros em anos anteriores; e Tangara cayana (Linnaeus, 1766), espécie em situação dúbia, pois apesar de registrada em sete meses, sempre teve baixa freqüência e não foi observada em anos anteriores.

Residentes de verão: Chaetura andrei Berlepsch \& Hartert, 1902 e Tyrannus melancholicus Vieillot, 1819 foram registrados seguidamente durante os meses mais quentes do ano, ausentando-se nos meses frios.

Ocasionais: doze espécies foram registradas com freqüência extremamente baixa (0,01 ou 0,02): Coccyzus euleri (Cabanis, 1873), Furnarius rufus (Gmelin, 1788), Synallaxis spixi Sclater, 1856, Machetornis rixosa (Vieillot, 1819), Myiodynastes maculatus (Müller, 1776), Elaenia sp., Platycichla flavipes (Vieillot, 1818), Turdus amaurochalimus Cabanis, 1851, Turdus albicollis Vieillot, 1818, Cyclarhis gujanensis (Gmelin, 1789), Tangara peruviana (Desmarest, 1806) e Piranga flava (Vieillot, 1822). Outras duas, apesar de aparecerem com freqüência um pouco mais elevada - Parula pitiayumi (Vieillot, 1817), com 0,07 de freqüência e Tachyphonus coronatus (Vieillot, 1822), com 0,10, tiveram os registros concentrados em poucos meses.

Aves que sobrevoam: oito espécies não foram observadas utilizando-se de qualquer recurso oferecido pela área, e apenas passaram em vôo sobre o local de estudo. No caso de Vanellus chilensis (Molina, 1782), uma pequena população habitou durante quase todo o período de estudo (salvo o verão), um gramado a cerca de $400 \mathrm{~m}$ do ponto de observação. É provável que também Coragyps atratus (Bechtein, 1793) se utilize dos arredores imediatos da área de estudo; há bairros vizinhos densamente ocupados por edifícios, no alto dos quais a espécie pode nidificar (HILl \& SCHERER-NeTO 1991). Phalacrocorax olivaceus (Gmelin, 1789) teve 0,60 de aparecimento, freqüência notavelmente alta se comparada tanto com os registros anteriores da espécie (um único avistamento entre 1978 e julho de 1990) quanto com as freqüências de sobrevôo de outras aves aquáticas durante o período: 0,13 para Casmerodius albus (Gmelin, 1789), 0,02 para Nycticorax nycticorax (Linnaeus, 1758) e 0,25 para Dendrocygna viduata (Linnaeus, 1766). A direção de vôo seguida por essas quatro espécies aquáticas indica a ocorrência de movimentação entre os lagos do Parque do Ibirapuera e do Jardim Botânico (no PEFI) e entre os lagos do Ibirapuera e as represas Billings e Guarapiranga, no sul da cidade; o biguá e as garças citadas reproduzem-se no PEFI (ARGEL-DEOLIVEIRA 1992). Uma outra espécie, Leistes superciliaris (Bonaparte, 1850), foi vista uma só vez, voando para sul, provavelmente para a beira das represas onde deve encontrar seu ambiente preferido. Progne chalybea (Gmelin, 1789), também foi vista uma vez, voando em linha reta, a grande altura. 
Tabela II. Aves registradas no bairro do Planalto Paulista (São Paulo) em 1978, 1982-89 e de janeiro a julho de 1990. Foram excluidas as aves que na tabela I apresentam freqüência igual ou superior a 0.90 , que por serem comuns em geral não eram registradas durante observações não sistematizadas. Espécies não registradas entre agosto de 1990 e julho de 1991 estão assinaladas com um asterisco.

\begin{tabular}{|c|c|}
\hline Espécies & Registros \\
\hline Phalacrocorax olivaceus & Visto uma vez, em jun-1989 \\
\hline Casmerodius albus & $\begin{array}{l}\text { Visto oito vezes, em 1984, } 1987 \text { e } 1989 \text { (mai, jun, } \\
\text { ago-out) }\end{array}$ \\
\hline Butorides striatus * & Visto uma vez, em out-1985 \\
\hline Dendrocygna viduata & Registrada 22 vezes, em seis anos (mar, mai-dez) \\
\hline Coragyps atratus & Visto três vezes, em 1978 e 1985 (jan, jun, set) \\
\hline Buteo magnirostris & $\begin{array}{l}\text { Registrado } 14 \text { vezes, em } 1989 \text { e } 1990 \text { (exceto em mar, } \\
\text { set, nov, dez) }\end{array}$ \\
\hline Milvago chimachima * & Visto uma vez, em jul-1983 \\
\hline Polyborus plancus * & Visto duas vezes, em 1984 e 1987 (mai) \\
\hline Falco sparverius * & Visto duas vezes, em mar-1985 e jun-1987 \\
\hline Vanellus chilensis & $\begin{array}{l}\text { Registrado } 38 \text { vezes, em sete anos (exceto em fev, mar, } \\
\text { nov) }\end{array}$ \\
\hline Melopsittacus undulatus * & Visto duas vezes, em 1985 (mai, ago) \\
\hline Aratinga aurea ${ }^{*}$ & Vista duas vez, em abr-1985 \\
\hline Amazona aestiva & Vista uma vez, em ago-1989 \\
\hline Piaya cayana & Vista uma vez, em jul-1989 \\
\hline Guira guira * & $\begin{array}{l}\text { Registrado } 23 \text { vezes em mai-out-1987; } 7 \text { em 1982,1984 e } \\
1985 \text { (mar-mai, ago, nov) }\end{array}$ \\
\hline Otus choliba * & Registrada uma vez, em jul-1990 \\
\hline Streptoprocne zonaris & $\begin{array}{l}\text { Registrada cinco vezes, em 1978, } 1984 \text { e } 1985 \text { (jun, } \\
\text { ago-out) }\end{array}$ \\
\hline Chaetura andrei & Vista 41 vezes, em quatro anos (mar, abr, set-dez) \\
\hline Eupetomena macroura & Vista 62 vezes, em cinco anos (exceto em jan, fev) \\
\hline Chlorostilbon aureoventris * & Visto uma vez, em abr-1987 \\
\hline Leucochloris albicollis * & Visto uma vez, em mar-1985 \\
\hline Furnarius rufus & Visto uma vez, em fev-1983 \\
\hline Satrapa icterophrys * & Vista duas vezes, em 1984 (mai, set) \\
\hline Machetornis rixosa & Vista 15 vezes, em quatro anos (exceto em fev, abr, nov) \\
\hline Tyrannus savana * & Visto duas vezes, em 1984 e 1985 (jan, set) \\
\hline Tyrannus melancholicus & $\begin{array}{l}\text { Registrado } 17 \text { vezes, em seis anos (exceto em fev, mai, } \\
\text { jul-set) }\end{array}$ \\
\hline Myiozetetes similis & Visto oito vezes, em 1985-87 (abr-jul, set) \\
\hline Myiarchus tyrannulus * & Visto duas vezes, em mar-1987 \\
\hline Todirostrum cinereum & Registrado três vezes, em 1984 e 1989 (mai, jul, ago) \\
\hline Serpophaga subcristata & Registrada 45 vezes, em quatro anos (exceto em jan, fev) \\
\hline Elaenia flavogaster & Registrada quatro vezes, em 1985 e 1987 (jul, nov) \\
\hline Camptostoma obsoletum & Registrado nove vezes, em 1984 (abr-jul) \\
\hline Notiochelidon cyanoleuca & Vista 128 vezes, em seis anos, todos os meses \\
\hline Mimus saturninus * & Visto duas vezes, em nov-1983 e dez-1984 \\
\hline Turdus amaurochalinus & $\begin{array}{l}\text { Visto nove vezes, em 1984, } 1985 \text { e } 1987 \text { (abr, mai, jul, } \\
\text { ago, nov) }\end{array}$ \\
\hline Turdus albicollis & Visto uma vez, em mai-1987 \\
\hline Cyclarhis gujanensis & Registrado duas vezes, em 1985 e 1986 (ago) \\
\hline Parula pitiayumi & Registrada quatro vezes, em abr- 1987 \\
\hline Thraupis palmarum & Registrado 19 vezes, em quatro anos (mar-jul, set) \\
\hline Thlypopsis sordida & Vista 12 vezes, em quatro anos (mar-mai, jul, set, dez) \\
\hline Serinus canaria * & Visto uma vez, em abr-1985 \\
\hline Estrilda astrild & Registrada 39 vezes, em seis anos (exceto em jan, fev) \\
\hline
\end{tabular}


Escapes: dois psitacídeos registrados Brotogeris versicolurus (Müller, 1776) e Amazona aestiva (Linnaeus, 1758), não são nativos da região da cidade de São Paulo, certamente tratando-se de indivíduos escapados de cativeiro. Ambos, principalmente o segundo, são populares como animais de estimação.

Das 18 espécies registradas na área, mas não durante as observações padronizadas, oito podem ser consideradas ocasionais, pelas poucas vezes em que foram avistadas: Piaya cayana (Linnaeus, 1766), Myiozetetes similis (Spix, 1825), Otus choliba (Vieillot, 1817), Chlorostilbon aureoventris (d'Orbigny \& Lafresnaye, 1838), Leucochloris albicollis (Vieillot, 1818), Satrapa icterophrys (Vieillot, 1818), Myiarchus tyrannulus (Müller, 1776) e Mimus saturninus (Lichtenstein, 1823). Seis apenas sobrevoaram: Butorides striatus (Linnaeus, 1758), Milvago chimachima (Vieillot, 1816), Polyborus plancus (Miller, 1777), Falco sparverius (Linnaeus, 1758), Streptoprocne zonaris (Shaw, 1796) e Tyrannus savana (Linnaeus, 1766). Três são obviamente escapes: Melopsittacus undulatus (Shaw, 1805), Aratinga aurea (Gmelin, 1789) e Serinus canaria (Linnaeus, 1758). Quanto a Guira guira (Gmelin, 1788), ao menos entre março e outubro de 1987, um pequeno bando fixou-se na área de estudo; a espécie pode ser considerada residente durante esse período.

Caracterização ecológica da avifauna: a tabela III resume informações da bibliografia sobre a biologia das espécies que, entre 1978 e 1991, de alguma forma utilizaram a área como local de alimentação, reprodução e/ou repouso. Excetuando os escapes e as que apenas sobrevoaram de passagem a área, são 48 espécies.

Predominam as aves onívoras que consomem insetos e frutos $(46 \%$ das espécies consideradas), seguidas pelas insetívoras (29\%). Há ainda espécies granívoras (8\%) e espécies onívoras que, além de insetos alimentam-se de néctar (11\%) ou de grãos (4\%). Uma espécie, Buteo magnirostris, é geralmente considerada carnívora na bibliografia, embora BELTZER (1990) tenha constatado a predominância de grandes insetos em sua dieta.

A maioria das espécies é de borda de mata e/ou vegetações secundárias (27, ou $56 \%$ ); onze são de ambientes abertos (23\%) e seis ocorrem em todas essas fisionomias (13\%). Há ainda três espécies introduzidas que se asselvajaram (6\%) e que, no Brasil, são características de ambientes urbanos. Uma espécie (2\%), Turdus albicollis, segundo a bibliografia consultada é típica de mata.

Quanto aos estratos explorados para alimentação e nidificação, nota-se o pouco uso do solo e do estrato herbáceo. Das 13 espécies (27\%) que aí buscam alimento, apenas sete (15\%) exploram exclusivamente esses estratos. Duas espécies alimentam-se no espaço aéreo (4\%) e a grande maioria (39 espécies, ou $81 \%$ ) forrageiam todo o tempo ou parte dele nos estratos arbustivo e arbóreo. De forma semelhante, apenas uma espécie (2\%), Zonotrichia capensis, tem por hábito nidificar no solo. É interessante, porém, que em ambiente urbano seja freqüentemente observada nidificando em vasos suspensos, entre folhagem. Ao menos seis $(15 \%)$ das espécies nidificam preferencial ou ocasionalmente em edificações humanas. 
Tabela III. Dados ecológicos sobre as aves observadas no bairro do Planalto Paulista (São Paulo) entre 1978 e 1991. Excetuam-se escapes e espécies que sobrevoam apenas de passagem.

\begin{tabular}{|c|c|c|c|c|}
\hline Espécie & Dieta & Habitat & Estrato de alimentação & Estrato de nidificação \\
\hline Buteo magnirostris & carn & bo se & v & v \\
\hline Columba livia & gran & ur & $\mathrm{s}$ & $E$ \\
\hline Columbina talpacoti & gran & aa & $\mathrm{s}$ & $B \vee E$ \\
\hline Brotogeris tirica & gran & bo & v & v \\
\hline Coccyzus euleri & inse & se & $B \vee$ & $B \vee$ \\
\hline Piaya cayana & inse & bo se & $B \vee$ & v \\
\hline Guira guira & inse & aa & $\mathrm{s}$ & V \\
\hline Otus choliba & inse & bo se & $B \vee$ & v \\
\hline Chaetura andrei & inse & aa & A & $V E$ \\
\hline Eupetomena macroura & oni III & bo & $B \vee$ & $B \vee$ \\
\hline Chlorostilbon aureoventris & oni III & bo se & $B \vee$ & $B \vee$ \\
\hline Leucochloris albicollis & oni III & bo se & $B \vee$ & $B \vee$ \\
\hline Amazilia lactea & oni III & bo & $B \vee$ & B \\
\hline Furnarius rufus & inse & aa & $\mathrm{s}$ & v \\
\hline Synallaxis spixi & inse & bo & $B$ & B \\
\hline Machetornis rixosa & inse & aa & s & v \\
\hline Satrapa icterophrys & oni I & bo se & B & $B \vee$ \\
\hline Tyrannus melancholicus & onil & bo se aa & v & v \\
\hline Myiodynastes maculatus & oni 1 & bo & v & v \\
\hline Myiozetetes similis & oni I & bo se & $B \vee$ & v \\
\hline Pitangus sulphuratus & oni I & bo se aa & S B V & v \\
\hline Myiarchus tyrannulus & oni I & bo se & $B \vee$ & v \\
\hline Todirostrum cinereum & inse & se & v & v \\
\hline Serpophaga subcristata & inse & bo & v & $B \vee$ \\
\hline Elaenia flavogaster & oni I & bo se aa & $B \vee$ & $B \vee$ \\
\hline Elaenia sp. & onil & bo se & $B \vee$ & $B \vee$ \\
\hline Camptostoma obsoletum & oni I & bo & v & v \\
\hline Notiochelidon cyanoleuca & inse & aa & A & $E$ \\
\hline Troglodytes aedon & inse & aa & B & $E$ \\
\hline Mimus saturninus & oni I & aa & $S B V$ & $B \vee$ \\
\hline Platycichla flavipes & onil & bo se & v & $? B$ \\
\hline Turdus rufiventris & oni I & bo & S B & $B \vee$ \\
\hline Turdus amaurochalinus & onil & bo aa & S B & B \\
\hline Turdus albicollis & onil & ma & B & $? \mathrm{~B}$ \\
\hline Cyclarhis gujanensis & oni I & bo se & v & v \\
\hline Molothrus bonariensis & oni II & aa & S B & - \\
\hline Parula pitiayumi & inse & bo se & $B \vee$ & v \\
\hline Coereba flaveola & oni III ${ }^{1}$ & bo se & $B \vee$ & $B \vee$ \\
\hline Tangara peruviana & onil & bo se & B & ? \\
\hline Tangara cayana & onil & bo se & $B \vee$ & $B \vee$ \\
\hline Thraupis sayaca & oni $1^{2}$ & se a a & $\mathrm{BV}$ & $B \vee$ \\
\hline Thraupis palmarum & onil & bo se aa & v & v \\
\hline Piranga flava & onil & aa & v & v \\
\hline Tachyphonus coronatus & oni I & bo se & B & B \\
\hline Thlypopsis sordida & oni I & bo se & B V & $B \vee$ \\
\hline Zonotrichia capensis & oni II & aa & S B & S B \\
\hline Passer domesticus & onill & ur & $\mathrm{s}$ & $E$ \\
\hline Estrilda astrild & gran & ur & S & $B \vee$ \\
\hline
\end{tabular}

Legenda: carn =predominantemente carnívora; gran = grãos e sementes de frutos carnosos; inse = unicamente artrópodos ou com proporção muito pequena de outros tipos de alimento; oni = parcialmente insetívora, com proporção considerável de outros itens alimentares (oni $\mathbf{I}=$ frutos; oni II = grãos; oni III = néctar); ma = mata, capœeirão; bo = borda de vegetação florestal; se =vegetação arbustivo-arbórea secundária (capoeira); $\mathbf{a a}=$ áreas abertas; $\mathbf{u r}=$ áreas urbanas; $\mathbf{S}=$ solo e herbáceo; $\mathbf{B}=$ arbustivo: $\mathbf{V}=$ arbóreo; $\mathbf{E}=$ edificações; $\mathbf{A}=$ aéreo; ${ }^{1}=$ inclui também uma certa porcentagem de fruto; ${ }^{2}=$ inclui também uma certa porcentagem de folhas e brotos.

Bibliografia consultada: Forshaw 1973; MeYer de SChauensee \& Phelps 1978; Willis 1979; FITZPATRICK 1980; SiCK 1985; IsLeR \& IsleR 1987; GRANTSAU 1988; RIDGely \& TUDOR 1989; MOTTA-JÚNIOR 1991; RODRIGUES 1991. 
A predominância de espécies caraterísticas de borda de mata indica que, no ambiente urbano do Planalto Paulista, a principal feição ambiental a determinar a composição da avifauna é a presença da vegetação arbórea. O fato desta ser composta em grande parte por plantas exóticas perde importância perante o fato mais significativo de estarmos tratando de um ambiente cuja fisionomia foi totalmente gerada pela ação humana, o que por si só já exclui a possibilidade de fixação daquelas espécies mais especializadas quanto a ambiente e alimentação. Nota-se que predominam espécies com dietas flexíveis, como os onívoros e os insetívoros não especializados. Os dois grupos que poderiam ser chamados de especialistas, os granívoros e os insetívoros que se alimentam em vôo, exploram fontes alimentares que não são afetadas de forma negativa pela urbanização, muito pelo contrário.

Avifauna e arborização urbana: das 67 espécies registradas na área, apenas 23, pouco mais de um terço, são residentes certos ou prováveis, que permanecem na área durante todo o ano, explorando os recursos alimentares por ela oferecidos e aí reproduzindo-se.

A presença das outras espécies é temporária. São aves que se deslocam e que durante esses deslocamentos atravessam a área. Natureza e forma de realização dos deslocamentos são diversificadas.

Há espécies que apenas sobrevoam a área ao se trasladarem entre locais de ambiente propício para sua fixação, como é o caso, por exemplo, das espécies de ambientes aquáticos. A maioria, porém, utiliza algum recurso da área durante sua passagem, seja alimento, seja abrigo na vegetação, seja simplesmente um poleiro para descanso.

Algumas espécies são claramente migratórias, como Chaetura andrei e Tyrannus melancholicus. Outras devem também sê-lo, como Leucochloris albicollis, Coccyzus euleri, Myiodynastes maculatus, Machetornis rixosa, Platycichla flavipes, Turdus amaurochalinus, Turdus albicollis, Tachyphonus coronatus, Piranga flava e Tangara peruviana, para as quais há na literatura menção de hábitos migratórios em maior ou menor grau (WILLIS 1979; SICK 1984; ISLER \& ISLER 1987).

Mas há espécies não migratórias com ocorrência esporádica, como Otus choliba, Piaya cayana, Furnarius rufus, Synallaxis spixi, Cyclarhis gujanensis e Parula pitiayumi. São todas espécies que ocorrem nas áreas verdes paulistanas (Argel-de-Oliveira 1987; Matarazzo-Neuberger 1990b; Höfling \& CAMARgo 1993) e do entorno da cidade (MATARAZZO-NEUBERGER 1990a), onde possivelmente são residentes e se reproduzem. Talvez os indivíduos observados ocasionalmente nos bairros, como no Planalto Paulista, sejam aqueles nascidos em áreas verdes que, não achando aí espaço para fixar território, precisam dispersar-se em busca de ambiente favorável para o estabelecimento definitivo. Deve existir, portanto, um fluxo constante dessas aves errantes, das áreas verdes em direção a áreas menos arborizadas.

Mesmo transitória, a presença de aves migrantes e dispersantes demonstra que a arborização urbana não é só fundamental para a manutenção dos níveis 
populacionais da fauna no plano estritamente local. Ela desempenha um papel relevante na sobrevivência de indivíduos que se movimentam dentro de uma área muito maior, auxiliando, em última análise, a movimentação gênica.

Em um bairro como o Planalto Paulista, a vegetação arbórea e arbustiva, apesar de nada ter de notável (como já se disse, esse não chega a ser classificado como bairro-jardim) é suficiente para fornecer recursos para 34 espécies de ambiente florestal, como demonstra a classificação ecológica acima. É claro que esse número é baixo quando comparado com a avifauna existente em áreas próximas ainda recobertas por vegetação nativa (por exemplo, as 188 espécies assinaladas por HöfLING \& LENCIONI [1992] em Salesópolis, na Serra do Mar), mas não interessa aqui fazer uma comparação entre ambientes naturais e antrópicos. Ambientes antrópicos são necessariamente simplificados e moldados de forma a atender principalmente às exigências de uma única espécie. Apesar do ambiente urbano ser um mal necessário, existe a possibilidade de mitigar os efeitos de sua existência ao menos para algumas espécies da avifauna nativa. E, sem dúvida, um bairro arborizado tem condições de fornecer recursos para um número muito maior de espécies de aves do que locais mais densamente construídos.

A importância do verde urbano na cidade de São Paulo vai além dos limites da própria cidade. A Floresta Atlântica, ambiente de elevados biodiversidade e grau de endemismo, ainda hoje pode ser encontrada às portas da mancha urbana, variando apenas, de região para região, seu estado de conservação ou grau de recomposição. A cidade está inserida em seu entorno e sujeita à visitação ou permanência de aves provenientes de áreas externas a ela. Em seus parques e bairros têm sido registradas aves raras ou de biologia pouco conhecida, como Tangara peruviana (presente estudo) e Laniisoma elegans (Lo 1994).

É evidente, assim, a importância a qualidade da vegetação dentro da mancha urbana de São Paulo e a necessidade não só de sua conservação como do incremento de sua capacidade de sustentação da avifauna silvestre.

Dentro deste contexto, a criação e a manutenção de áreas verdes públicas são importantes, mas têm valor limitado caso sejam medidas isoladas. É necessária a melhoria da vegetação da cidade como um todo, merecendo atenção, por exemplo, a arborização viária e a vegetação de pequenos espaços livres nos equipamentos urbanos. Deve haver incentivo ainda à preservação da vegetação de lotes particulares.

Valorizar a vegetação deve ser um dos pontos de destaque de projetos que prevejam o rearranjo da ocupação urbana, sendo um meio eficaz de manutenção da biodiversidade dentro do ambiente urbano.

AGRADECIMENTOS. Parte das considerações aqui tecidas foi desenvolvida durante estudos financiados pela Ecoplan Arquitetura e Planejamento S/C Ltda. As discussões com José Ricardo de Carvalho e Júlio F. Scottini foram fundamentais. A José Fernando Pacheco agradeço a leitura crítica do manuscrito. 


\section{REFERÊNCIAS BIBLIOGRÁFICAS}

ARGEl-DE-OlIVEIRA, M.M. 1987. Observações preliminares sobre a avifauna da cidade de São Paulo. 1986. Bolm CEO (4): 6-39.

- 1992. O ninhal do Parque Estadual das Fontes do Ipiranga, São Paulo (Estado de São Paulo, Brasil). Bolm CEO (8): 16-21.

FITZPATRICK, J.W. 1980. Foraging behavior of neotropical tyrant flycatchers. Condor 82: 43-57.

Forshaw, J.M. 1973. Parrots of the world. Melbourne, Lansdowne, 584p.

Grantsau, R. 1989. Os beija-flores do Brasil. Rio de Janeiro, Expressão e Cultura, $2^{\mathrm{a}}$ ed., 233p.

Hill, J.R., \& P. SCHERER-NeTO. 1991. Black Vultures nesting on skyscrapers in Southern Brazil. J. Field Ornithol. 62 (2): 173-176.

HöFling, E. \& F. LENCIONI. 1992. Avifauna da floresta atlântica, região de Salesópolis, Estado de São Paulo. Revta bras. Biol. 52 (3): 361-378.

Höfling, E. \& H.F. de A. Camargo. 1993. Aves no Campus. São Paulo, Instituto de Biociências da Universidade de São Paulo, 126p.

Ihering, H. von. 1898. As aves do Estado de São Paulo. Revta Mus. paul. 3: 113-500.

IsLER, M.L. \& P.R. IsLER. 1987. The tanagers. Oxford, Oxford University, 404p.

Lo, V.K. 1994. Ocorrência de Laniisoma elegans (Thunberg, 1823) (Cotingidae) e Fluvicola nengeta (Linnaeus, 1766) (Tyrannidae) no município de São Paulo, SP. Bolm CEO (10): 36-40.

Matarazzo-Neuberger, W.M. 1990a. Aves de uma seção de mata atlântica, Santo André, SP. Anais do Simpósio de ecossistemas da costa sul e sudeste brasileira, 2. São Paulo, ACIESP, vol. 1, p. 385-394.

- 1990b. Lista das aves observadas na Cidade Universitária "Armando Salles de Oliveira", São Paulo, Brasil. Revta Brasil. Biol. 50 (2): 507-511.

Meyer de Schauensee, R. \& W.H. Phelps JR. 1978. A guide to the birds of Venezuela. Princeton, Princeton University, 424p.

Mrtchell, M.H. 1957. Observations on birds of Southeastern Brazil. Toronto, University of Toronto, 258p.

MOTtA-JÚnior, J.C. 1991. A exploração de frutos como alimento por aves de mata ciliar numa região do Distrito Federal. Tese de Mestrado, não publicada, Universidade Estadual Paulista, Rio Claro, VII + 121 p.

Pelzeln, A. 1871. Zur Ornithologie brasiliens. Viena, A. Pilchlers Witwe \& Sohn, 462p.

PInTO, O.M. DE O. 1937. Catálogo das aves do Brasil. Revta Mus. paul. 22: 1-566.

1944. Catálogo das aves do Brasil. 2. Ordem Passeriformes. Departamento de Zoologia da Secretaria da Agricultura, Indústria e Comércio, São Paulo, 700p.

1950. Peter W. Lund e sua contribuição à ornitologia brasileira. Pap. 
av. Depto Zool., São Paulo, 9 (18): 269-283.

Ridgely, R.S. \& G. TudoR. 1989. The birds of South America. Oxford, Oxford University, vol. 1, 516p.

Rodrigues, M. 1991. Ecologia alimentar de traupídeos (Aves: Thraupinae) na mata atlântica de São Paulo. Tese de Mestrado, não publicada, Universidade Estadual de Campinas, Campinas, VII +84p.

São Paulo. 1988. Vegetação significativa no Município de São Paulo. São Paulo, Secretaria do Meio Ambiente, Secretaria Municipal de Planejamento, 558 p.

SICK, H. 1984. Ornitologia brasileira: uma introdução. Brasília, Editora da Universidade de Brasilia, vol. 1 e 2, 827p.

WILLIS, E.O. 1979. The composition of avian communities in remanescent woodlots in Southern Brazil. Pap. Avuls Depto Zool., São Paulo, 33 (1): 1-25.

Recebido em 15.IX.1994; aceito em 08.II.1995. 